\title{
Achieving High-Frequency Optical Control of Synaptic Transmission
}

\author{
Skyler L. Jackman, Brandon M. Beneduce, Iain R. Drew, and Wade G. Regehr \\ Department of Neurobiology, Harvard Medical School, Boston Massachusetts 02115
}

The optogenetic tool channelrhodopsin-2 (ChR2) is widely used to excite neurons to study neural circuits. Previous optogenetic studies of synapses suggest that light-evoked synaptic responses often exhibit artificial synaptic depression, which has been attributed to either the inability of ChR2 to reliably fire presynaptic axons or to $\mathrm{ChR} 2$ elevating the probability of release by depolarizing presynaptic boutons. Here, we compare light-evoked and electrically evoked synaptic responses for high-frequency stimulation at three synapses in the mouse brain. At synapses from Purkinje cells to deep cerebellar nuclei neurons $(\mathrm{PC} \rightarrow \mathrm{DCN})$, light- and electrically evoked synaptic currents were remarkably similar for ChR2 expressed transgenically or with adeno-associated virus (AAV) expression vectors. For hippocampal $\mathrm{CA} 3 \rightarrow$ CA1 synapses, AAV expression vectors of serotype 1, 5 , and 8 led to light-evoked synaptic currents that depressed much more than electrically evoked currents, even though ChR2 could fire axons reliably at up to $50 \mathrm{~Hz}$. The disparity between optical and electrical stimulation was eliminated when ChR2 was expressed transgenically or with AAV9. For cerebellar granule cell to stellate cell (grc $\rightarrow$ SC) synapses, AAV1 also led to artificial synaptic depression and AAV9 provided superior performance. Artificial synaptic depression also occurred when stimulating over presynaptic boutons, rather than axons, at CA3 $\rightarrow$ CA1 synapses, but not at $\mathrm{PC} \rightarrow \mathrm{DCN}$ synapses. These findings indicate that $\mathrm{ChR} 2$ expression methods and light stimulation techniques influence synaptic responses in a neuron-specific manner. They also identify pitfalls associated with using ChR2 to study synapses and suggest an approach that allows optogenetics to be applied in a manner that helps to avoid potential complications.

Key words: AAV; channelrhodopsin; optogenetics; short-term plasticity; synapse

\section{Introduction}

The genetically encoded light-gated cation channel channelrhodopsin-2 (ChR2) is widely used both in vitro and in vivo to investigate neural circuits and to characterize synapses. ChR2 can be expressed in specific neuronal populations by the targeted injection of viral vectors and by using Cre-expressing driver lines (Fenno et al., 2011; Madisen et al., 2012). Light can then be used to control neural activity with high temporal and spatial precision (Boyden et al., 2005). In this way, ChR2 can be used to activate defined presynaptic inputs selectively, enabling characterization of synapses that are not amenable to study by conventional approaches (Petreanu et al., 2007; Xia et al., 2011; Mathews et al., 2012) because, for many synapses, paired recording or selective electrical stimulation of specific presynaptic inputs is impractical.

The use of ChR2 for characterization of synapses, however, has been limited by a perception that ChR2 does not allow reli-

\footnotetext{
Received Nov. 5, 2013; revised April 25, 2014; accepted April 30, 2014.

Author contributions: S.L.J. and W.G.R. designed research; S.L.J., B.M.B., and I.R.D. performed research; S.L.J. analyzed data; S.L.J. and W.G.R. wrote the paper.

This work was supported by the National Institutes of Health Grant R01 NS032405 to W.G.R., Training Grant NS007484 to S.L.J, and a Leonard and Isabelle Goldenson Fellowship to S.L.J. We thank Kimberly MCDaniels for help with mouse breeding; Justin Brousseau, Kaytee Flick, and Hannah Goulart for stereotaxic injections; Jasmine Vazquez for figure illustrations; and the University of Pennsylvania Vector Core, Arpiar Saunders, and Bernardo Sabatini for providing AAV vectors. The authors declare no competing financial interests.

Correspondence should be addressed to Wade G. Regehr, Department of Neurobiology, Harvard Medical School, 220 Longwood Avenue, Boston MA 02115. E-mail: wade_regehr@hms.harvard.edu.

DOI:10.1523/JNEUROSCI.4694-13.2014

Copyright $\odot 2014$ the authors $\quad 0270-6474 / 14 / 347704-11 \$ 15.00 / 0$
}

able synaptic activation at the high firing frequencies that occur physiologically. Optically evoked synaptic currents have been shown to depress more than those evoked electrically (Zhang and Oertner, 2007; Cruikshank et al., 2010; Olsen et al., 2012), but the reason for this disparity is not known. It has been proposed that ChR2 desensitization may prevent reliable action potential generation during high-frequency stimulation (Olsen et al., 2012). Alternatively, it is thought that the slow kinetics of ChR2 could broaden action potentials and increase the initial probability of release (Zhang and Oertner, 2007), particularly when the presynaptic boutons are directly activated with light.

For many optogenetic approaches, it is vital to identify and overcome limitations of ChR2 to activate synapses at physiological frequencies. One approach to overcoming limitations in light activation has been to engineer new variants of ChR2 with less desensitization and faster kinetics (Nagel et al., 2005; Lin et al., 2009; Gunaydin et al., 2010). Here, we evaluate the ability of ChR2 to activate synaptic inputs at high frequencies and determined whether widely available ChR2 variants can be used to activate synapses at physiological frequencies. We compared electrically and optically evoked responses at three central synapses and found that the performance of ChR2 was synapse dependent, but there were important general principles. Stimulating axons with ChR2 reliably triggered presynaptic action potentials, yet light-evoked synaptic responses showed artificial depression in some cases when certain AAV serotypes were used to drive expression. When ChR2 was expressed transgenically or 
with AAV serotype 9, light-evoked responses more closely resembled responses evoked by conventional electrical stimulation. Although we have identified potential complications associated with using ChR2, our findings suggest a strategy to avoid such problems when using optogenetics to study synapses.

\section{Materials and Methods}

ChR2 expression. All animals were handled in accordance with federal guidelines and protocols approved by Harvard University. Mice of either sex of the following strains were used: wild-type (WT) C57BL/6N (Charles River Laboratories), as well as transgenic lines (Jackson Laboratories) Thy1-ChR2-YFP (B6.Cg-Tg(Thy1-COP4/EYFP)18Gfng/J),

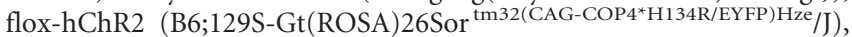
PCP2-Cre (B6.Cg-Tg(Pcp2-cre)3555Jdhu/J), CaMKII-Cre (B6.Cg$\mathrm{Tg}$ (Camk2a-cre)T29-1Stl/J), and the cerebellar granule-cell-specific $\alpha 6$ Cre line (Aller et al., 2003). The following AAV vectors were obtained from the University of Pennsylvania Vector Core: AAV1-CAG.ChR2Venus.WPRE.SV40, AAV5-CAG.ChR2-Venus.WPRE.SV40 and AAV9CAG.ChR2-Venus.WPRE.SV40, AAV1-hSyn.hChR2(H134R)-EYFP. WPRE.hGH,AAV1-CMV.PI.Cre.rBG,AAV1-CB7.CI.TurboRFP.WPRE. rBG. AAV8.EF1a.FAS.ChR2(H134R)-mCherry was provided by Bernardo Sabatini (Saunders et al., 2012).

Mice at postnatal day 16 (P16) to $\mathrm{P} 30$ were anesthetized by intraperitoneal injection of a mixture of ketamine/xylazine/acepromazine (100/ $10 / 3 \mathrm{mg} / \mathrm{kg}$ ) supplemented with $1-4 \%$ isoflurane at $0.6-1.4 \mathrm{~L} / \mathrm{min}$. To target expression to lobule $\mathrm{V}$ of the cerebellar cortex, a small craniotomy was made $1.35 \mathrm{~mm}$ caudal from lambda at the midline. Using a stereotaxic instrument (Kopf Instruments), a fine glass capillary needle was lowered $0.8 \mathrm{~mm}$ below the surface of the brain and then slowly retracted to $0.7 \mathrm{~mm}$ after $3 \mathrm{~min}$. To target expression to the hippocampal CA3 region, injection coordinates were $2.69 \mathrm{~mm}$ rostral and $3 \mathrm{~mm}$ lateral (left) from lambda; the needle was lowered $2.9 \mathrm{~mm}$ and then retracted to $2.8 \mathrm{~mm}$. Viruses were diluted with PBS and $0.2 \mu \mathrm{l}$ (cerebellum) or $1 \mu \mathrm{l}$ (hippocampus) of virus suspension was delivered at a rate of $0.1 \mu \mathrm{l} / \mathrm{min}$ using a microliter syringe (Hamilton) and a microsyringe pump controller (WPI). Five to $10 \mathrm{~min}$ after bolus injection, the needle was slowly retracted. The scalp incision was sutured and postinjection analgesics (buprenophrine, $0.05 \mathrm{mg} / \mathrm{kg}$ ) were administered subcutaneously for $48 \mathrm{~h}$.

ChR2 expression levels were sufficient to optically evoke synaptic responses from PCs and CA3 cells within 1 week of injection. Due to the difficulty of recording from the deep cerebellar nuclei (DCN) in older animals, all recordings were performed 10-14 d after injection. Hippocampal recordings could be made in older animals, so we tested a larger range of wait times (1-7 weeks after injection), but found that the properties of optically evoked transmission did not vary significantly with wait time. ChR2 expression was lower in cerebellar granule cells, for which we found that $\sim 3$ weeks were required to optically evoke synaptic responses; therefore, we performed experiments 3-4 weeks after injection.

Acute slice preparation. For hippocampal and stellate cell recordings, animals were deeply anesthetized using isoflurane and decapitated. Brains were removed and placed in an ice-cold dissecting solution containing the following (in $\mathrm{mM}$ ): $82.7 \mathrm{NaCl}, 65$ sucrose, $23.8 \mathrm{NaHCO}_{3}, 23.7$ glucose, $6.8 \mathrm{MgCl}_{2}, 2.4 \mathrm{KCl}, 1.4 \mathrm{NaH}_{2} \mathrm{PO}_{4}$, and $0.5 \mathrm{CaCl}$. Then, 300 $\mu \mathrm{m}$-thick transverse hippocampal slices or $250-\mu \mathrm{m}$-thick transverse cerebellar slices were made in ice-cold dissecting solution. In hippocampal slices, a cut was made in stratum radiatum between CA3 and CA1 to prevent recurrent excitation. Slices were incubated at $32^{\circ} \mathrm{C}$ for $30 \mathrm{~min}$ in artificial CSF (ACSF) containing the following (in $\mathrm{mM}$ ): $125 \mathrm{NaCl}, 26$ $\mathrm{NaHCO}_{3}, 25$ glucose, $2.5 \mathrm{KCl}, 2 \mathrm{CaCl}_{2}, 1.25 \mathrm{NaH}_{2} \mathrm{PO}_{4}$, and $1 \mathrm{MgCl}_{2}$, adjusted to $315 \mathrm{mOsm}$. For DCN recordings, animals were anesthetized by intraperitoneal injection of ketamine/xylazine/acepromazine, intracardially perfused with $32^{\circ} \mathrm{C}$ ACSF, and then $300-\mu \mathrm{m}$-thick sagittal cerebellar slices were made in warm ACSF. Slices were incubated at $32^{\circ} \mathrm{C}$ for 30 min in ACSF with $1.5 \mathrm{~mm} \mathrm{CaCl}_{2}$ to facilitate comparison with previous studies (Person and Raman, 2012) and allowed to equilibrate to room temperature for $>30 \mathrm{~min}$. Experiments were performed at $33 \pm 1^{\circ} \mathrm{C}$ with flow rates of $4 \mathrm{ml} / \mathrm{min}$. After recording, slices were imaged with an Axio Imager 2 fluorescent microscope (Zeiss) to assess the extent of AAVmediated expression and images were analyzed using ImageJ.

Electrophysiology. Data were acquired using a Multiclamp 700B amplifier (Molecular Devices) digitized at $20 \mathrm{kHz}$ with an ITC-18 (Instrutech). Voltage-clamp recordings were low-pass filtered at $2 \mathrm{kHz}$. Acquisition was controlled by custom software written in IgorPro (generously provided by Matthew Xu-Friedman, SUNY Buffalo). Whole-cell recordings were obtained using patch pipettes $(3-6 \mathrm{M} \Omega$ ) pulled from borosilicate capillary glass (WPI) with a Sutter P-97 horizontal puller. To record EPSCs in hippocampal CA1 and stellate cells, inhibition was blocked with picrotoxin $(20 \mu \mathrm{M})$, cells were voltage clamped at $-60 \mathrm{mV}$, and patch pipettes were filled with an internal recording solution containing the following (in mM): $110 \mathrm{CsCl}, 35 \mathrm{CsF}, 10$ EGTA, 10 HEPES, and 2 QX-314, pH 7.2, 315-320 mOsm. For current-clamp recordings, the internal solution contained the following (in $\mathrm{mm}$ ): $150 \mathrm{~K}$-gluconate, 3 $\mathrm{KCl}, 10$ HEPES, 0.5 EGTA, 3 MgATP, 0.5 GTP, 5 phosphocreatine-tris2, and 5 phosphocreatine- $\mathrm{Na} 2$, with the $\mathrm{pH}$ adjusted to 7.2 with $\mathrm{NaOH}$. To record synaptically driven firing in CAl neurons, inhibition was blocked with picrotoxin $(20 \mu \mathrm{M})$; to record ChR2-elicited spikes in CA3 neurons, excitation was also blocked with NBQX (5 $\mu \mathrm{M})$ and CPP $(2.5 \mu \mathrm{M})$. IPSCs were recorded in DCN neurons using the same K-gluconate internal solution, cells were voltage clamped at $0 \mathrm{mV}$, and NBQX $(5 \mu \mathrm{M}), \mathrm{CPP}$ $(2.5 \mu \mathrm{M})$, and strychnine $(2 \mu \mathrm{M})$ were included in the bath solution. Series resistance was monitored in voltage-clamp recordings with a $2 \mathrm{mV}$ hyperpolarizing pulse. For both electrical and optical stimuli, four to 10 trials were typically conducted for each interstimulus interval and voltage-clamp recordings were averaged over trials. For extracellular stimulation, glass monopolar electrodes $(0.5-1 \mathrm{M} \Omega$ ) were filled with ACSF and controlled with a stimulus isolation unit (A360; WPI). Electrical stimulus artifacts were deleted for display. Averaged paired-pulse and train EPSC data are displayed with double exponential or polynomial curves fit in IgorPro.

ChR2 stimulation. Slices expressing ChR2 were stored in low light. To stimulate ChR2, a $100 \mathrm{~mW}$ DPSS analog-controllable $473 \mathrm{~nm}$ blue laser (OptoEngine) was coupled through the excitation pathway of a BX51WI upright microscope (Olympus). Laser light was focused onto slices through a $60 \times$ water-immersion objective to produce an $80 \mu \mathrm{m}$ maximum diameter spot. The spot size was adjusted using a dual-slit light modulator (Till Photonics). For hippocampal EPSC recordings, the area of the laser illumination and the intensity of the electrical stimulation were adjusted to produce initial EPSCs of $<200 \mathrm{pA}$. To assess the laser intensity at the sample, an optical power meter (Ophir; Vega) was used to measure the absolute steady-state intensity below the objective. A photodiode was then used to measure the relative intensity during steadystate illumination and during a $0.5 \mathrm{~ms}$ laser pulse. The output of the photodiode was used to determine the absolute intensity during $0.5 \mathrm{~ms}$ pulses.

\section{Results}

\section{Assessing short-term synaptic plasticity using virally expressed ChR2}

To determine the utility of ChR2 for studying short-term synaptic plasticity, we compared optically and electrically evoked synaptic transmission at three types of synapses with diverse properties. We studied the inhibitory synapse between cerebellar Purkinje cells and DCN neurons (the PC $\rightarrow$ DCN synapse) that conveys the output of the cerebellar cortex. PCs are spontaneously active cells capable of firing at high frequencies and contain voltage-gated potassium channels that rapidly repolarize after action potentials; PC axons are myelinated (Palay and ChanPalay, 1974). We also studied the excitatory synapse between the unmyelinated axon of CA3 and CA1 pyramidal cells (the CA3 $\rightarrow$ CA1 synapse), which is arguably the most extensively studied synapse in the mammalian brain (Creager et al., 1980; Manabe et al., 1993; Oertner et al., 2002). Finally, we studied excitatory synapses between cerebellar granule cells and stellate 
cells (the grc $\rightarrow$ SC synapse). Granule cells are not spontaneously active, but are capable of firing rapidly and their axons, commonly known as parallel fibers, are unmyelinated in mice and rats (Palkovits et al., 1971; Palay and Chan-Palay, 1974; Wyatt et al., 2005).

We targeted a ChR2-Venus fusion protein to the either the cerebellar cortex or the CA3 region of the hippocampus by stereotaxic injection of an AAV vector (AAV1-CAG.ChR2-Venus). After waiting for expression of ChR2-Venus (see Materials and Methods), slices were cut and axons were activated with a spot of light $\sim 200-500 \mu \mathrm{m}$ from the recorded neuron either electrically with an extracellular electrode or optically with an $80-\mu \mathrm{m}$ diameter spot of $473 \mathrm{~nm}$ laser light focused through the microscope objective (0.5 ms, $160 \mathrm{~mW} / \mathrm{mm}^{2}$; Fig. $1 A-C$, top) and synaptic responses were monitored with whole-cell recordings.

An important test of short-term plasticity is how synapses respond to trains because synapses are often repetitively activated by multiple presynaptic action potentials in vivo. At the $\mathrm{PC} \rightarrow \mathrm{DCN}$ synapse, PSCs evoked by $20 \mathrm{~Hz}$ electrical stimulation depressed modestly (Fig. $1 A$ ), as described previously for this synapse (Telgkamp and Raman, 2002). Remark-

ably, responses evoked by optical stimulation exhibited the same short-term plasticity and showed no signs of the artificial synaptic depression reported at other synapses (Cruikshank et al., 2010; Olsen et al., 2012). In contrast, there was a pronounced mismatch between optically and electrically evoked responses at the CA3 $\rightarrow$ CA1 synapse and the grc $\rightarrow$ SC synapse. When Schaffer collaterals were stimulated at $20 \mathrm{~Hz}$, electrically evoked PSCs facilitated throughout the train, whereas optically evoked PSCs facilitated transiently and then depressed (Fig. $1 B$ ). Similar results were seen at the grc $\rightarrow$ SC synapse (Fig. 1C), although differences between electrical and optical stimulation were somewhat less pronounced.

Although AAV expression vectors are perhaps the most popular method for driving ChR2 expression, the growing availability of ChR2 transgenic lines could enable optogenetic characterization of synapses. However, expression levels in transgenic animals are often lower than vector-driven expression levels. To assess the suitability of transgenic ChR2 expression for activating synapses, we expressed ChR2 in PCs either with AAV or transgenically (Fig. 2A) and compared optically evoked synaptic responses at the $\mathrm{PC} \rightarrow \mathrm{DCN}$ synapse. To express $\mathrm{ChR} 2$ in PCs, we crossed the PC-specific PCP2-Cre line with the Ai32 line (which we will refer to as "flox-hChR2"; Madisen et al., 2012) that drives Cre-dependent expression of ChR2(H134R)-EYFP. We found we could stimulate PC axons with trains of 10 and $50 \mathrm{~Hz}$ and optically evoked PSCs closely resembled electrically evoked PSCs (Fig. 2B). Therefore, in contrast to what has been reported at other synapses, at the $\mathrm{PC} \rightarrow \mathrm{DCN}$ synapse, ChR2 appears to be remarkably well suited for characterizing synaptic properties.

To explore the different performance of ChR2 between the $\mathrm{PC} \rightarrow \mathrm{DCN}$ synapse and the hippocampus, we more thoroughly
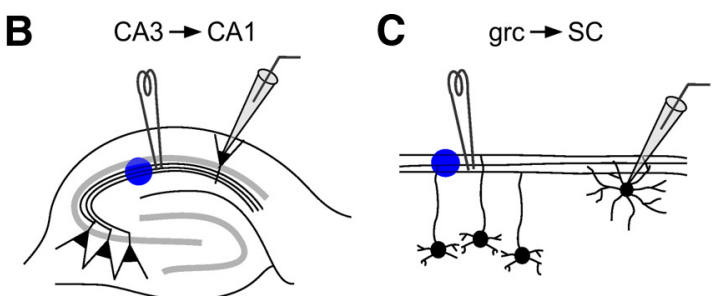

| I | | | | | | |

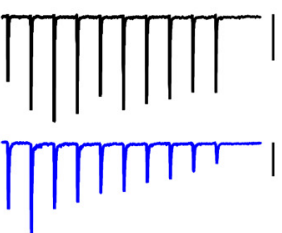

I I I I I I I I I I
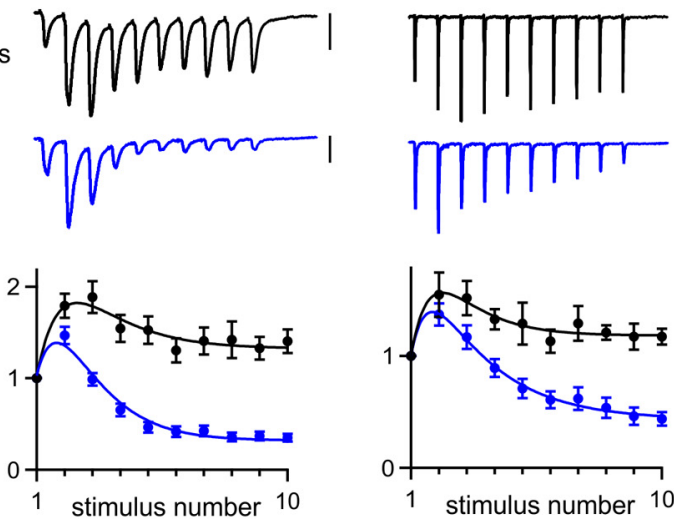

1 stimulus number 10

Figure 1. Comparing optically and electrically evoked synaptic plasticity at three central synapses. ChR2 was expressed in presynaptic cells using AAV1-ChR2. Axons were stimulated at $20 \mathrm{~Hz} 200-500 \mu \mathrm{m}$ from the postsynaptic cell, either electrically with an extracellular electrode or optically with blue light. Postsynaptic currents (PSCS) were measured in voltage clamp for the

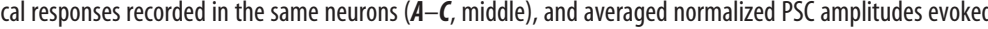
11,6 for $\boldsymbol{A}, 25,31$ for $\boldsymbol{B}$, and 10,13 for $\boldsymbol{C}$. Vertical scale bars, 100 pA. Data are expressed as average \pm SEM.

characterized optically evoked responses at the CA3 $\rightarrow$ CA1 synapse. AAV1 injections into the hippocampus resulted in robust expression of ChR2-Venus in the CA3 pyramidal neurons and their axons, similar to what we observed in cerebellar PCs (Fig. $3 A$ ). However, with $10 \mathrm{~Hz}$ stimulation, electrically evoked responses showed modest facilitation, whereas optically evoked responses depressed strongly (Fig. 3B, left). We found this surprising because ChR2 is capable of driving reliable firing at 10 $\mathrm{Hz}$ (Arenkiel et al., 2007). With $50 \mathrm{~Hz}$ stimulation, electrically evoked responses exhibited strong transient facilitation that was followed by sustained but only modestly facilitated synaptic responses, whereas optically evoked responses showed transient facilitation followed by strong depression (Fig. 3B, right). Optically evoked steady-state synaptic responses were more strongly attenuated for high-frequency stimulation.

To assess optically evoked short-term plasticity, we also used paired-pulse stimulation, a method often used to determine the initial release probability ( $p$ ) of synapses (Zucker and Regehr, 2002). Typically, low $p$ synapses facilitate, whereas high $p$ synapses depress. At the CA3 $\rightarrow$ CA1 synapse, electrical stimulation results in paired-pulse facilitation that peaks at approximately a twofold enhancement and decays to baseline with a time constant of $\sim 90 \mathrm{~ms}$ (Fig. 3C). Optically stimulating Schaffer collateral axons with pairs of flashes produced paired-pulse ratios that deviated from the electrically evoked curve for short interstimulus intervals (ISIs) but facilitated normally for ISIs of $50 \mathrm{~ms}$ and greater (Fig. 3C). Prominent depression was observed for an ISI of $10 \mathrm{~ms}$. These findings suggest that using ChR2 to assess the $p$ and paired-pulse plasticity of a synapse can be misleading (Zhang and Oertner, 2007; Varga et al., 2009; Cruikshank et al., 2010; Ellender et al., 2011; Ledri et al., 2012; Piñol et al., 2012). 
A AAV1-ChR2-Venus

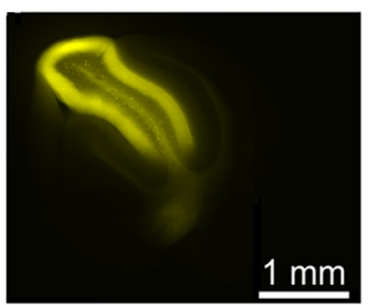

PCP2-Cre X flox-hChR2

B

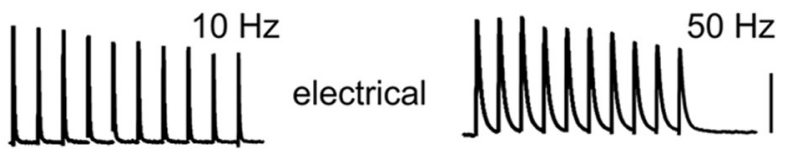

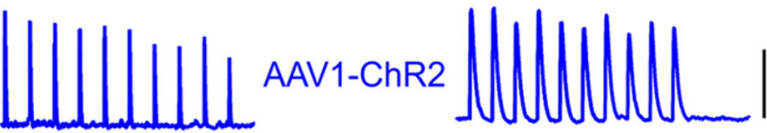
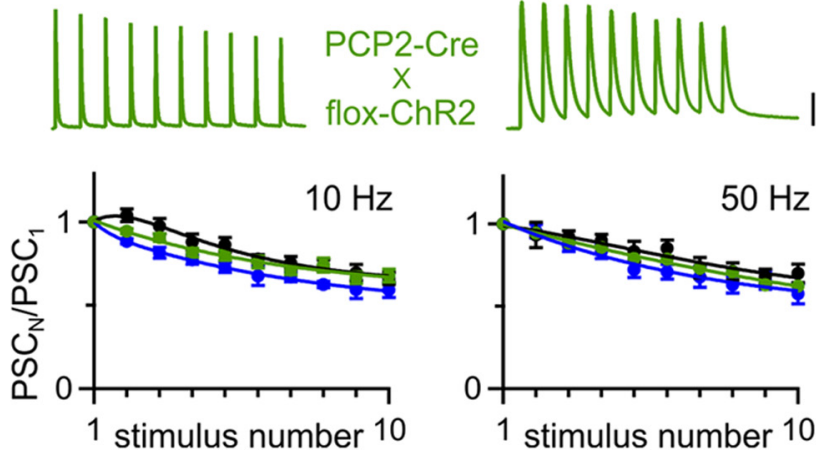

Figure 2. Optically evoked plasticity is normal at the $P C \rightarrow D C N$ synapse. $A$, Fluorescence images in sagittal cerebellar slices of ChR2-Venus expression after AAV1-ChR2 injection (left) and hChR2-YFP expression from a PCP2-Cre X flox-hChR2 mouse (right). $\boldsymbol{B}$, Top, Representative IPSCs evoked by electrical and optical stimulation of presynaptic axons, for AAV1- and transgenic-driven ChR2 expression. Scale bars, $1 \mathrm{nA}$ for electrical and PCP2-Cre X flox-hChR2, $100 \mathrm{pA}$ for AAV1-ChR2. Bottom, Averaged normalized PSC amplitudes from 10 and $50 \mathrm{~Hz}$ trains evoked electrically ( $n=11$ ) and optically (AAV1-ChR2, $n=6$; PCP2-Cre $\times$ flox-hChR2, $n=$ 14). Data are expressed as average \pm SEM.

AAV expression vectors affect synaptic plasticity

We wondered whether deficits in optically evoked synaptic plasticity resulted from the inability of ChR2 to drive presynaptic firing. To determine the reliability of optically evoked firing, we recorded from CA3 pyramidal cells in current clamp while stimulating with a $0.5 \mathrm{~ms}$ flash focused either over the soma or over the axon $\sim 500 \mu \mathrm{M}$ away in the stratum radiatum (Fig. $4 A$ ). Optical stimulation over either the soma or axon could elicit spikes. As reported previously, somatically induced spikes were preceded by a charging phase, whereas axonally induced spikes showed little prior depolarization (Lewis et al., 2009; Petreanu et al., 2009; Madisen et al., 2012), confirming that spikes were initiated far from the somatic recording pipette. Both stimulation methods elicited spikes, although axonal stimulation required brighter light (Fig. 4B). We worried that using bright light might reduce the reliability of generating multiple spikes because ChR2 inactivation increases with light intensity (Lin et al., 2009). However, maximal intensity light $\left(160 \mathrm{~mW} / \mathrm{mm}^{2}\right)$ reliably evoked axonal firing for ISIs of $20-500 \mathrm{~ms}$ (Fig. $4 C, D$ ). Even an ISI of 10 ms elicited pairs of spikes in most cells (11/13 cells) and CA3 axons could be driven reliably at frequencies up to $50 \mathrm{~Hz}$ (Fig. $4 E, F$ ).

If unreliable firing does not account for deficits in optically evoked short-term plasticity, this raised the possibility that our ChR2 expression vector changed the properties of synapses. In-
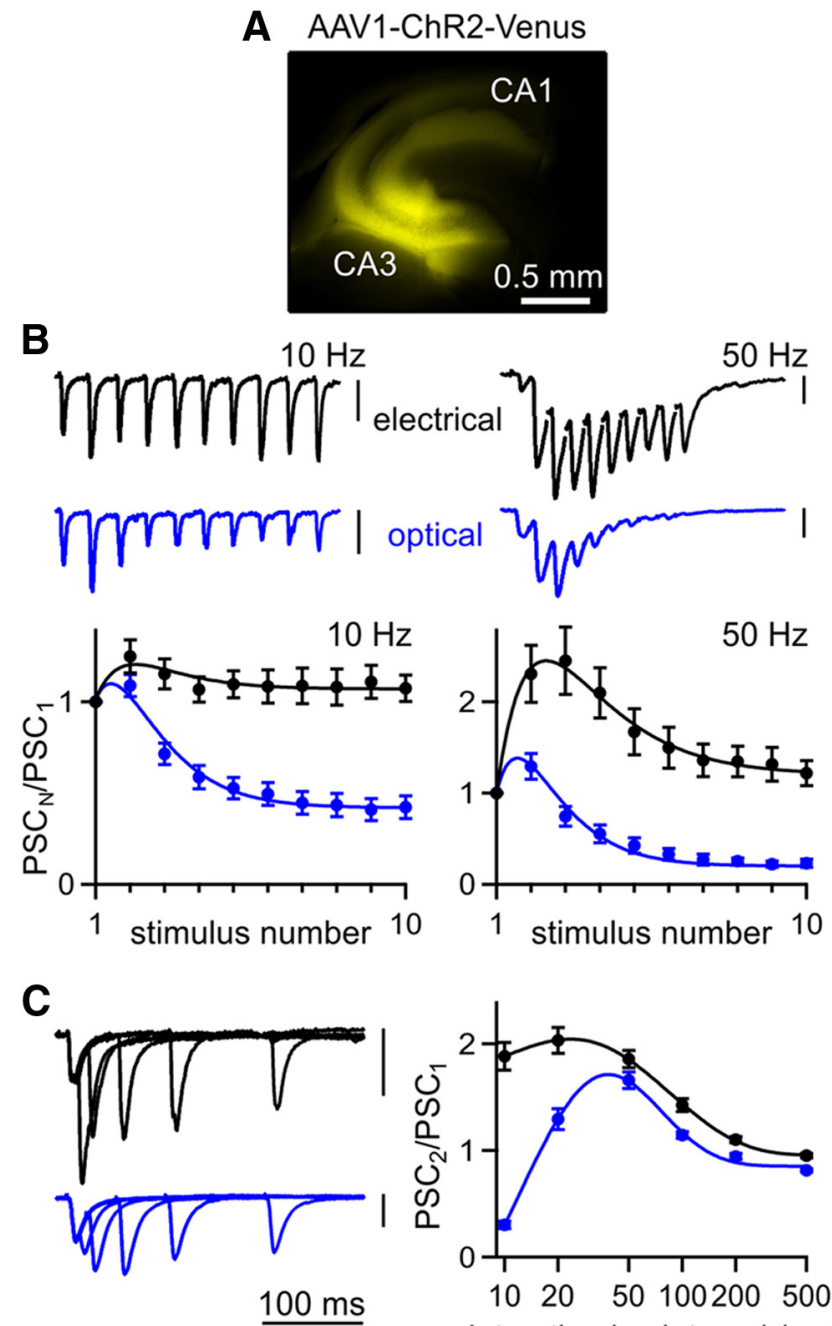

interstimulus interval (ms)

Figure 3. Optically evoked responses exhibit abnormal depression at the hippocampal $\mathrm{CA} 3 \rightarrow$ CA1 synapse. $\boldsymbol{A}$, Fluorescence image of ChR2-Venus expression in a transverse hippocampal slice after injection of AAV1-ChR2. B, Top, Representative EPSCs evoked by 10 and 50 $\mathrm{Hz}$ trains recorded from the same CA1 pyramidal neuron for both electrical and optical stimulation of Schaffer collateral axons. Bottom, Averaged normalized EPSC amplitudes during trains evoked electrically $(n=25)$ and optically $(n=31)$. C, Left, Representative EPSCs evoked optically and electrically by pairs of stimuli at $10-200 \mathrm{~ms} I S \mid$ recorded from the same neuron. Right, Averaged paired-pulse ratios evoked electrically $(n=89)$ and optically $(n=126)$. Vertical scale bars, $100 \mathrm{pA}$. Data are expressed as average \pm SEM.

terestingly, our observed deficits in optically evoked short-term plasticity closely resembled those of previous studies in which vectors were also used to express ChR2 (Zhang and Oertner, 2007; Cruikshank et al., 2010).

One possible way to reconcile our observations is if AAV alters synaptic plasticity at the CA3 $\rightarrow$ CA1 synapse. If this is the case, then one might expect altered plasticity regardless of whether axons are stimulated optically or electrically. On the contrary, we found that, on average, there was a slight reduction in the amount of paired-pulse plasticity between electrically evoked responses in uninjected and injected animals, but it was not statistically significant ( $p>0.1$ for all ISIs, unpaired Student's $t$ test; Fig. 5E). However, this is not a fair test of the hypothesis that AAV alters synaptic properties because optical and electrical stimulation activate different axons. Light activates only ChR2-expressing axons that originate in the CA3 region near the injection site, whereas electrical stimulation activates both expressing and non- 
A
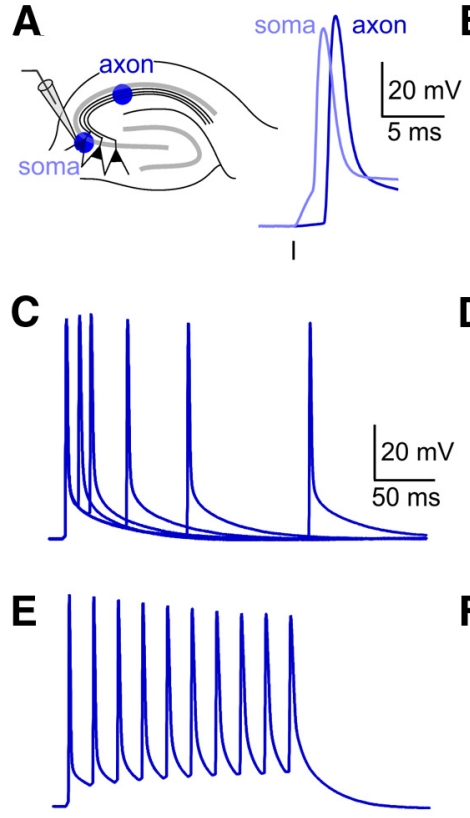

B
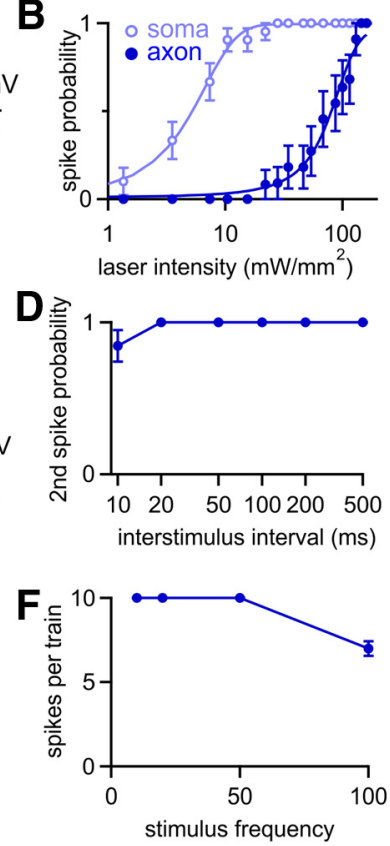

Figure 4. Axonal illumination reliably elicits action potentials. $A$, Experimental configuration. Whole-cell current clamp recordings were made from CA3 hippocampal pyramidal cells with ChR2-Venus expression driven by AAV1-ChR2. Cells were stimulated optically with light focused either over the cell soma or $\sim 500 \mu \mathrm{m}$ away over the stratum radiatum. $\boldsymbol{B}$, Less light was required to generate action potentials when the cell soma was illuminated ( $n=21)$, but illumination over axons produced action potentials in all cells at the brightest intensities $(n=$ 11). C, Representative spikes evoked by pairs of flashes delivered at $10-200 \mathrm{~ms}$ intervals. D, At the brightest laser intensity, the second flash generated a spike for all ISIs except $10 \mathrm{~ms}$ ( $n=$ 13). $\boldsymbol{E}$, Representative spike train elicited by flashes delivered at $50 \mathrm{~Hz}$. Same scale as in $\boldsymbol{C} . \boldsymbol{F}$, Average number of spikes elicited by 10 flashes at frequencies from $10 \mathrm{to} 100 \mathrm{~Hz}(n=7)$. Data are expressed as average \pm SEM.

expressing axons that could arise at a distance from the injection site. Therefore, electrically evoked plasticity could be minimally affected if AAV changes plasticity in infected cells in a cell autonomous manner or even if plasticity is altered in all cells near the injection site. If AAV does alter synaptic properties, then the short-term plasticity of electrically activated responses would only be impaired if most of the electrically activated axons are from cells influenced by AAV.

We therefore tested the hypothesis that AAV can alter shortterm plasticity by determining whether AAV expression that results in widespread infection of many CA3 neurons alters electrically activated short-term plasticity. In experiments in which we used AAV1 to express ChR2, we identified slices that had a large number of expressing axons based on ChR2-Venus fluorescence intensity and the ability to optically evoke large synaptic currents in CA1 pyramidal cells ( $>1 \mathrm{nA}$ with maximal intensity illumination; Fig. 5A); 8 of 126 cells satisfied this criteria. We found that synaptic currents evoked by single electrical stimuli appeared normal, but paired-pulse facilitation was disrupted (Fig. 5C). In similar experiments, we expressed the diffusible cytosolic red fluorescent protein TurboRFP and identified slices with many fluorescently labeled fibers in the CA1 region (Fig. $5 B)$. AAV1-RFP also decreased the facilitation of electrically evoked responses (Fig. 5D,F). Together with our ability to reliably elicit action potentials optically at high frequency, these findings suggest that AAV can alter short-term synaptic plasticity. Although, in these experiments, more CA3 neurons express proteins at higher levels than in most of our optical experiments, they
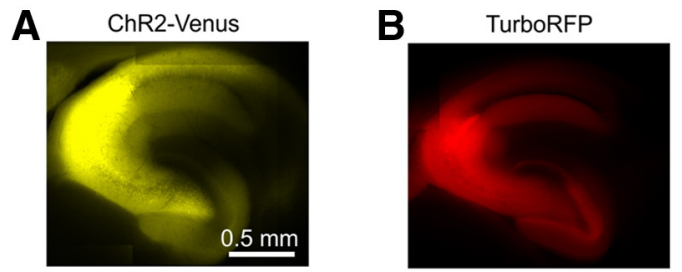

electrically-evoked responses
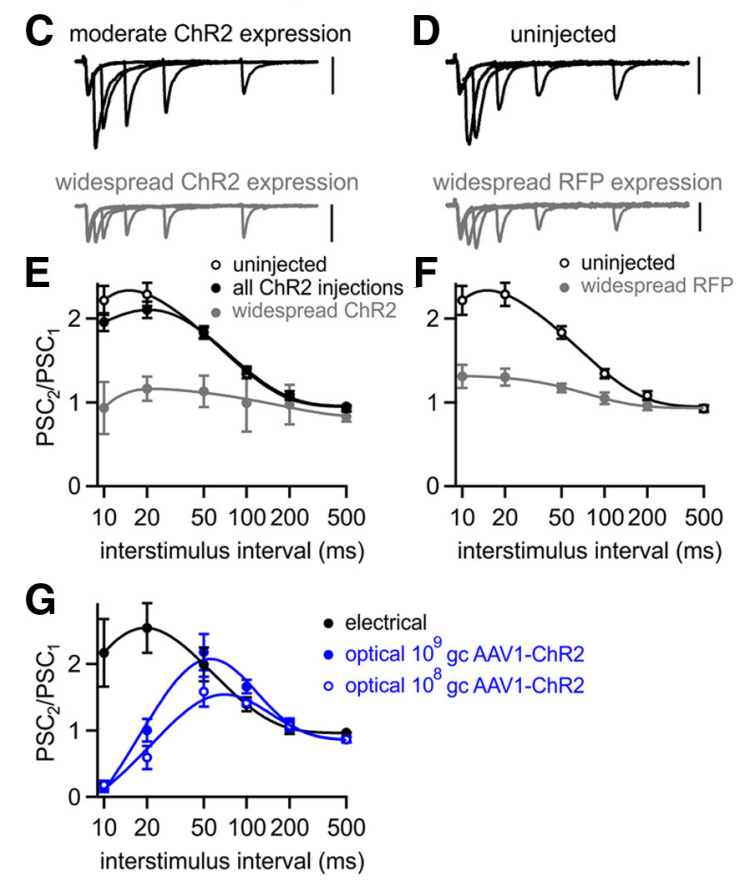

Figure 5. AAV1-driven expression of either ChR2 or a fluorescent protein can alter plasticity at the $\mathrm{CA} 3 \rightarrow$ CA1 synapse. Fluorescence images of widespread ChR2-Venus $(\boldsymbol{A})$ and TurboRFP expression ( $\boldsymbol{B}$ ) after AAV1 injections. C, D, EPSCs evoked electrically by pairs of stimuli at $10-$ $200 \mathrm{~ms}$ ISI recorded from CA1 pyramidal cells in slices with the indicated properties. All scale bars, $100 \mathrm{pA}$. $E$, Averaged electrically evoked paired-pulse ratios from uninjected animals $(n=$ 25), all AAV1-ChR2 injected animals ( $n=89$ ), and AAV1-ChR2 injected animals with widespread expression $(n=8) . \boldsymbol{F}$, Averaged electrically evoked paired-pulse ratios, from uninjected animals (from $\boldsymbol{E}$ ) and AAV1-TurboRFP-injected animals with widespread expression $(n=19)$. G, When the viral load of AAV1-ChR2 injections was lowered to $10^{9} \mathrm{gc}(n=13)$ and $10^{8} \mathrm{gc}(n=4)$, optically stimulating axons evoked responses, which still exhibited deficits compared with electrically evoked responses recorded from the same slices $(n=6)$. Data are expressed as average \pm SEM.

support the hypothesis that AAV1 can alter the properties of CA3 $\rightarrow$ CA1 synapses.

The changed synaptic properties that we observed with AAV1 could be a general result of viral infection and transduction of neurons or could somehow reflect higher expression levels driven by AAV1. Because strong ChR2 expression is a requirement for reliable activation of neurons, in most of our experiments, we injected high viral loads of $\sim 10^{10}$ genome copies (gc) with strong promoters designed to produce the high expression levels (Johansen et al., 2010; Xia et al., 2011; Harrison et al., 2012). We tested whether changes to synaptic plasticity could be avoided by lowering the viral load of our injections and thus the levels of $\mathrm{ChR} 2$ expression. In these experiments, the electrically evoked paired-pulse plasticity was similar to that of uninjected animals (which could be explained by a low fraction of fibers being influenced by AAV1), but we still observed deficits in optically evoked paired-pulse plasticity (Fig. 5G). Further lowering the viral load of injections to $\sim 10^{8} \mathrm{gc}$ produced so little ChR2 expression that synaptic responses could be optically evoked in only 1 of 5 in- 


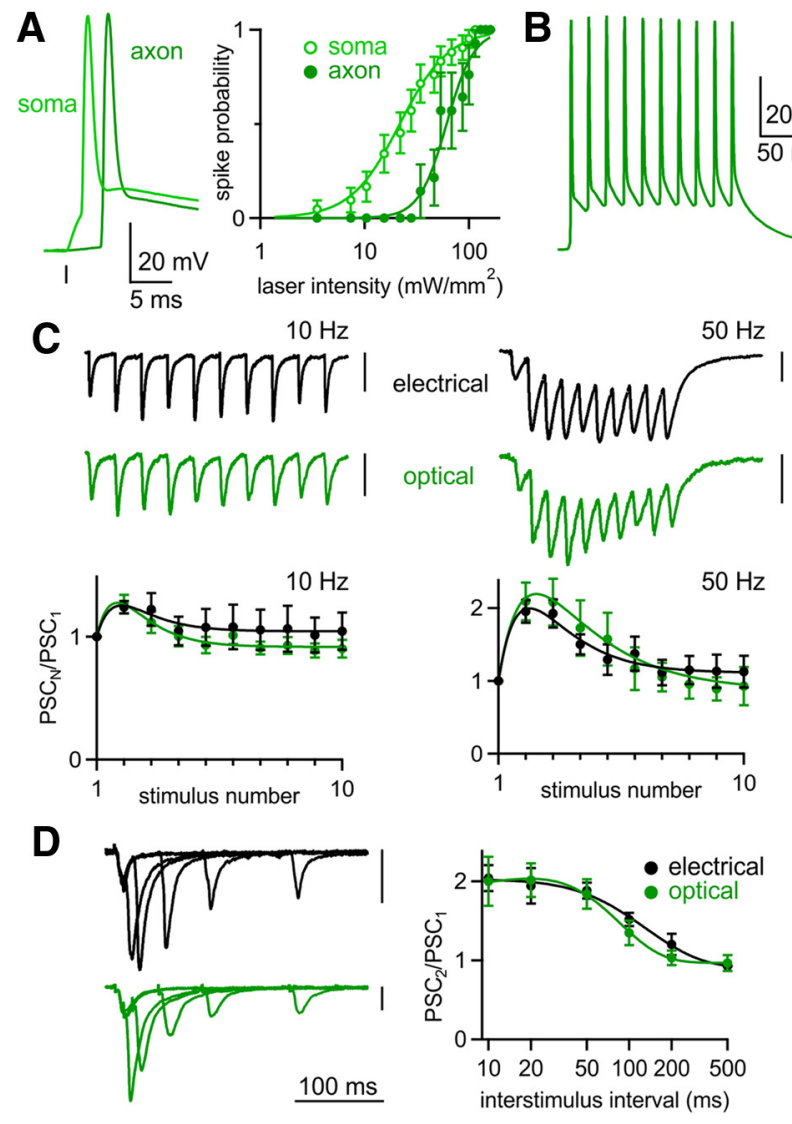

Figure 6. Optically evoked plasticity is normal with transgenic ChR2 expression. $\boldsymbol{A}$, Left, Whole-cell current clamp recordings from CA3 hippocampal pyramidal cells in Thy1-ChR2 mice. Cells were stimulated optically with light focused either over the cell soma (open circle) or 500 $\mu \mathrm{m}$ away over the stratum radiatum (closed circle). Right, The probability of optically evoking a spike in CA3 pyramidal cells for either somatic or axonal illumination (soma, $n=25$; axon, $n=10) . \boldsymbol{B}$, Representative spike train elicited by flashes delivered at $50 \mathrm{~Hz}$. C, Top, Representative EPSCs evoked by 10 and $50 \mathrm{~Hz}$ stimulation of Schaffer collateral axons; both stimulation methods were recorded from the same CA1 pyramidal neuron. Bottom, Averaged normalized EPSC amplitudes during trains evoked electrically $(n=6)$ and optically $(n=9)$ at 10 and $50 \mathrm{~Hz}$. D, Left, Representative EPSCs evoked optically and electrically by pairs of stimuli at $10-200 \mathrm{~ms}$ ISI recorded from the same neuron. Right, Averaged paired-pulse ratios evoked electrically $(n=6)$ and optically $(n=9)$. Vertical scale bars, $100 \mathrm{pA}$. Data are expressed as average \pm SEM.

jected mice, but deficits in short-term plasticity were still evident (Fig. 5G). This suggests that if ChR2 is to be used to activate axons, then AAV1-induced deficits cannot be avoided by reducing expression levels.

\section{Short-term plasticity is unaffected by transgenic ChR2 expression at $\mathrm{CA} 3 \rightarrow \mathrm{CA} 1$ synapses}

In light of our findings that AAV1-driven gene expression can alter synaptic properties, we tested the possibility that such problems could be avoided by transgenic expression of ChR2. We used a transgenic mouse line that expresses ChR2 in hippocampal pyramidal neurons (Thy1-ChR2; Arenkiel et al., 2007). We again confirmed that axonal illumination could elicit firing (Fig. 6A). Current-clamp recordings from CA3 pyramidal neurons showed that brighter light was required to generate spikes when illuminating the axon compared with somatic illumination (Fig. 6A, right). As with AAV-injected animals, optical stimulation elicited reliable firing at frequencies up to $50 \mathrm{~Hz}$ (Fig. 6B). However, for 10 and $50 \mathrm{~Hz}$ train stimulation, both optically and electrically evoked EPSCs facilitated throughout the train (Fig. 6C). This
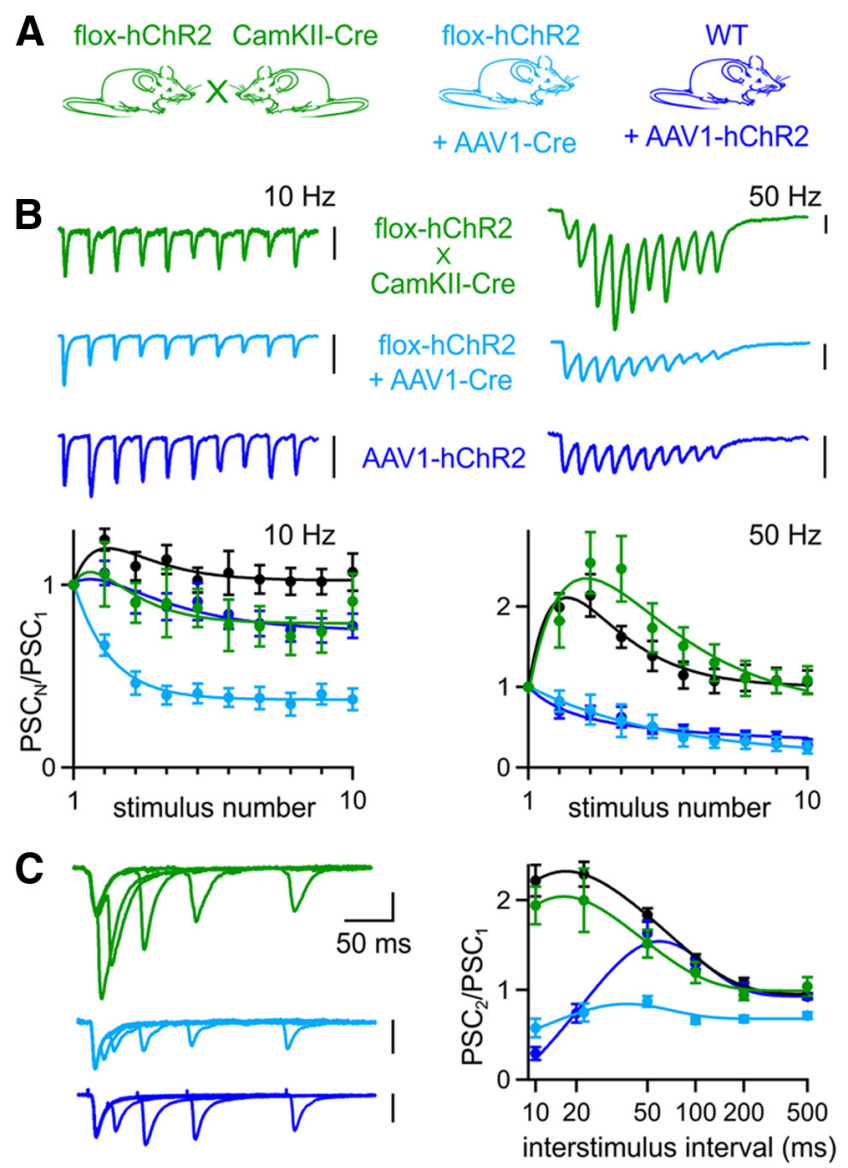

Figure 7. Optically evoked synaptic plasticity is normal for Cre-dependent ChR2 expression in the absence of AAV. A, To express ChR2 in CA3 neurons, Cre-dependent flox-hChR2 mice were either crossed with CaMKII-Cre mice or injected with AAV1-Cre. To control for the mutated variant hChR2 expressed by flox-hChR2 mice, WT mice were also injected with AAV1-hChR2. $\boldsymbol{B}$, Top, Representative EPSCs evoked by optical trains delivered over axons at 10 and $50 \mathrm{~Hz}$. Bottom, Averaged normalized EPSC amplitudes during trains evoked optically (flox-hChR2 $\times$ CaMKII-Cre, $n=7$; flox-hChR2 + AAV1-Cre, $n=10 ;$ WT + AAV1-hChR2, $n=17$ ) and electrically (WT uninjected mice, $n=18$ ). C, Left, Representative EPSCs from pairs of stimuli delivered at $10-200 \mathrm{~ms}$ ISIs. Right, Average paired-pulse ratios for optical (flox-hChR2 $\times$ CaMKII-Cre, $n=7 ;$ flox-hChR2 + AAV-Cre, $n=18 ;$ WT + AAV-hChR2, $n=48$ ) and electrical stimulation (WT uninjected mice, $n=25$ ). The 20 ms data point for WT + AAV-hChR2 was offset laterally to be visible. Data are expressed as average \pm SEM.

differed markedly from AAV-driven ChR2 expression, in which optically evoked EPSC trains strongly depressed. In contrast to AAV-injected animals, optically evoked paired-pulse facilitation was normal in Thy1-ChR2 mice, even for an ISI of $10 \mathrm{~ms}$ (Fig. 6D). Our results with the Thy1-ChR2 indicate that ChR2 can be used to determine short-term synaptic plasticity of the $\mathrm{CA} 3 \rightarrow \mathrm{CA} 1$ synapse accurately.

Another way to assess the contribution of expression levels and to determine if AAV alters short-term plasticity is to use the Cre-dependent flox-hChR2 (Madisen et al., 2012), in which hChR2-EYFP expression may be "turned on" in CA3 neurons with an appropriate Cre-driver line (CaMKII-Cre; Xu et al., 2000) or by injecting an AAV that drives Cre expression (Fig. 7A). Either method should drive similar levels of transgenic ChR2 expression, allowing us to determine whether the difference between Thy1-ChR2 animals and AAV1-ChR2-injected animals results from different levels of expression. Because the flox-hChR2 mouse expresses the mutated H134R variant of ChR2 (hCHR2), which has slightly increased light sensitivity, decreased desensiti- 
zation and slower channel closing (Nagel et al., 2005; Lin, 2011), we also injected AAV1-hChR2-EYFP in WT mice as a control.

Optically evoked EPSCs facilitated during train stimulation in flox-hChR2 $\times$ CaMKII-Cre mice, but strongly depressed for 50 $\mathrm{Hz}$ stimulation in flox-hChR2 mice injected with AAV1-Cre and WT mice injected with AAV1-hChR2 (Fig. 7B). Optically evoked paired-pulse ratios in flox-hChR2 $\times$ CaMKII-Cre mice were similar to electrically evoked paired-pulse ratios in uninjected WT mice (Fig. 7C). In contrast, paired-pulse ratios were strongly depressed in flox-hChR2 mice injected with AAV1-Cre. In WT animals injected with AAV1-hChR2, paired-pulse ratios resembled those of WT animals injected with AAV1-ChR2 (Fig. 3), indicating that the different properties of the two variants did not affect optically evoked synaptic plasticity significantly. These data again illustrate that transgenically expressed ChR2 can be used to determine short-term plasticity, whereas AAV-driven expression of either Cre or hChR2 can alter synaptic properties.

\section{Strategies for avoiding AAV-induced changes to synaptic plasticity}

AAV vectors have become popular agents for gene delivery due to their ability to drive strong, stable, nontoxic gene expression. There is little evidence that AAV vectors affect synaptic transmission and AAV is often used to express ChR2 and other molecules for studies of synaptic transmission. However, it was reported recently that, in the mouse hippocampus, AAV-driven expression of GFP can impair inhibitory transmission by reducing GABA levels in vesicles (Ortinski et al., 2010). It is unclear to what extent AAV also affects excitatory synapses. Interestingly, AAVinduced changes to synaptic transmission depended on AAV serotype. AAV5 led to decreased synaptic inhibition, AAV9 did not, and AAV1 was not tested (Ortinski et al., 2010).

Thus far, our expression vectors were all serotype 1 , which we chose for its strong transduction efficiency in hippocampal neurons (Royo et al., 2008). We wondered whether the changes we observed in short-term plasticity might depend on AAV serotype. We therefore injected WT mice with vectors identical to the AAV1-ChR2 from Figures 1, 2, 3, 4, and 5, but with different viral serotypes (AAV5-CAG.ChR2-Venus and AAV9-CAG.ChR2Venus) and with AAV8-EF1a.FAS.ChR2(H134R)-mCherry. All three vectors produced strong expression in the hippocampus (Fig. 8A).

When ChR2 expression was driven by AAV5 and AAV8, optically evoked EPSCs depressed strongly during train stimulation (Fig. $8 B$ ) and there were deficits in paired-pulse facilitation (Fig. $8 C$ ). In marked contrast, when AAV9 was used to express ChR2, the responses to trains (Fig. $8 B$ ) and pairs of optical stimuli (Fig. $8 C$ ) more closely resembled electrical stimulation. Therefore, it appears that AAV1, AAV5, and AAV8 alter the properties of the CA3 $\rightarrow$ CA1 synapse, but AAV9 does not.

We investigated whether using AAV9 to express ChR2 is also effective at mitigating the synaptic depression observed with optically evoked trains at the grc $\rightarrow$ SC synapse (Fig. 9A). At this synapse, electrical stimulation at $10 \mathrm{~Hz}$ produced only very modest synaptic facilitation and $50 \mathrm{~Hz}$ stimulation produced facilitation that was initially large, but modest by the tenth stimulus (Fig. 9B). When AAV1-ChR2 was used, depression was apparent for $10 \mathrm{~Hz}$ optical trains and more prominent for $50 \mathrm{~Hz}$ trains (Fig. $9 B)$. When AAV9-ChR2 was used, light-evoked synaptic plasticity was similar to electrically evoked synaptic plasticity for the first 5 stimuli ( $p>0.1$, unpaired Student's $t$ test), but by the tenth stimulus, the PSCs depressed, although not as much as when AAV1 was used (Fig. 9B). These findings suggest that, for the
A
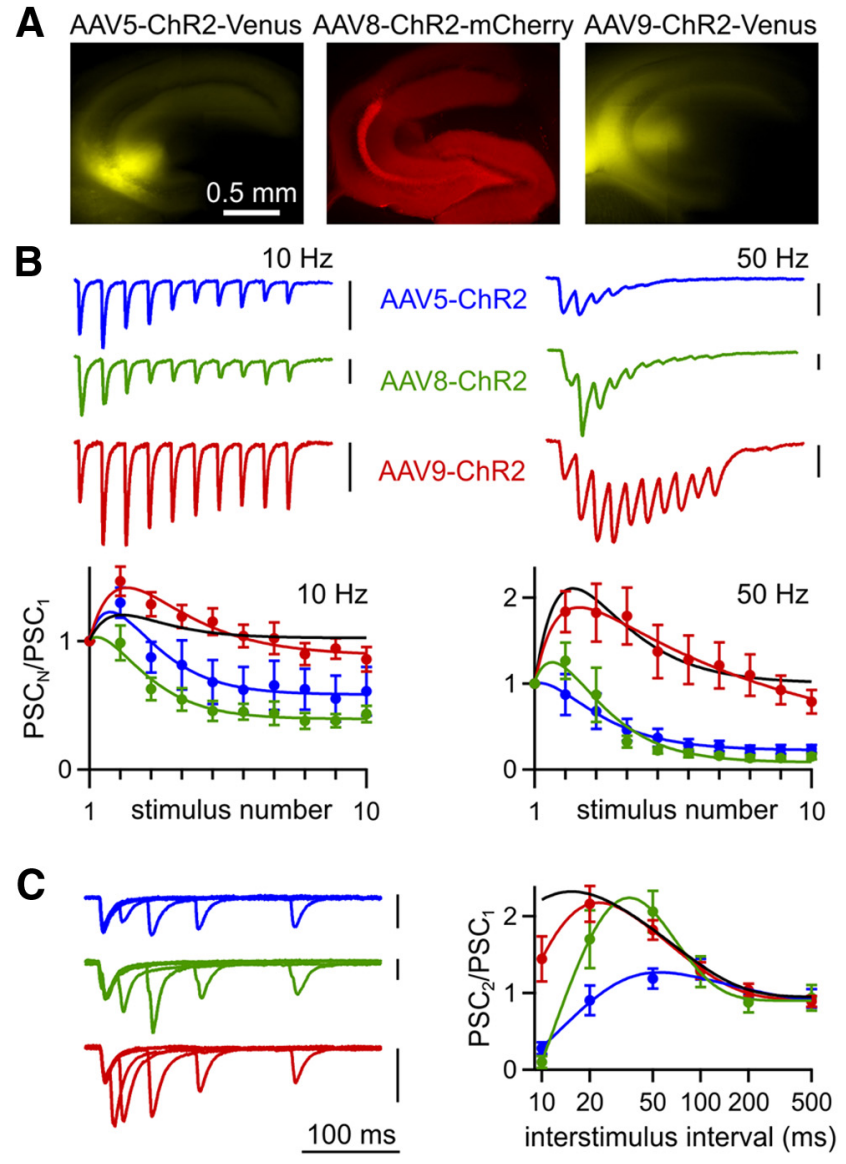

Figure 8. Effect of AAV serotype on optically evoked synaptic plasticity. $\boldsymbol{A}$, ChR2 expression after injection of AAV5-ChR2, AAV8, or AAV9-ChR2 in WT mice. $\boldsymbol{B}$, Top, Representative EPSCS evoked by optical trains delivered over axons at 10 and $50 \mathrm{~Hz}$. Bottom, Averaged normalized EPSC amplitudes during trains evoked optically (AAV5-ChR2, $n=6$; AAV8-ChR2, $n=7$; AAV9ChR2, $n=10$ ). Curve fit to electrical stimulation in uninjected animals (Fig. 7) is also shown for comparison. C, Left, Representative EPSCs from pairs of stimuli delivered at $10-200 \mathrm{~ms}$ ISIs. Right, Average paired-pulse ratios for optical stimulation (AAV5-ChR2, $n=6$;AAV8-ChR2, $n=$ 7; AAV9-ChR2, $n=14$ ) and curve fit for electrical stimulation (black, WT uninjected mice, Fig. 7). Vertical scale bars, $100 \mathrm{pA}$. Data are expressed as average \pm SEM.

grc $\rightarrow$ SC synapse, as in the CA3 $\rightarrow$ CA1 synapse, superior performance of ChR2 is achieved when it is expressed with AAV9 rather than AAV1.

We unsuccessfully attempted to determine whether transgenic ChR2 expression could also improve light-evoked responses at the grc $\rightarrow$ SC synapse. We crossed flox-hChR2 mice with $\alpha 6$-Cre mice (Aller et al., 2003) to express hChR2-EYFP selectively in cerebellar granule cells. We found that hChR2EYFP expressed, but at such low levels that we were unable to evoke PSCs with brief light pulses.

\section{Over-bouton illumination}

Although we found conditions that led to good agreement between optically and electrically evoked short-term plasticity at both $\mathrm{PC} \rightarrow \mathrm{DCN}$ and $\mathrm{CA} 3 \rightarrow \mathrm{CA} 1$ synapses, our standard approach was to stimulate axons far from the postsynaptic cell to avoid complications that may arise from directly stimulating presynaptic boutons. Previous studies suggest that over-bouton stimulation may alter synaptic plasticity either by changing the presynaptic waveform or by allowing direct influx of $\mathrm{Ca}^{2+}$ through ChR2 (Zhang and Oertner, 2007; Olsen et al., 2012). Despite this potential problem, over-bouton stimulation can be 

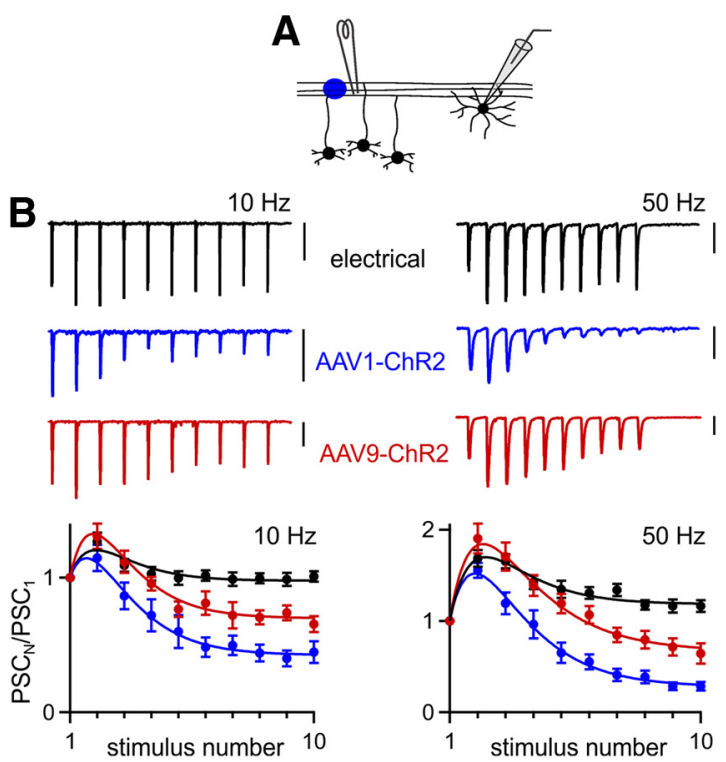

Figure 9. Effect of AAV serotype on optically evoked synaptic plasticity at the granule cell $\rightarrow$ stellate cell synapse. $\boldsymbol{A}$, Experimental configuration. Parallel fiber axons from cerebellar granule cells were stimulated $\sim 500 \mu \mathrm{m}$ from the recorded cell by laser illumination (blue circle) or with extracellular electrode and synaptic responses were monitored in voltage-clamp mode from stellate cells. ChR2 was expressed in granule cells by either AAV1-ChR2 or AAV9ChR2. B, Top, Representative EPSCs evoked by trains of 10 stimuli delivered by extracellular electrode or laser illumination at $10 \mathrm{~Hz}$ and $50 \mathrm{~Hz}$. Bottom, Averaged normalized EPSC amplitudes during trains evoked electrically $(n=10)$ and optically (AAV1-ChR2, $n=13$; AAV9-ChR2, $n=12$ ) at $10 \mathrm{~Hz}$ and $50 \mathrm{~Hz}$. Vertical scale bars, $100 \mathrm{pA}$. Data are expressed as average $\pm \mathrm{SEM}$.

much more effective at evoking synaptic responses, so many optogenetic studies stimulate synaptic transmission by illuminating directly over presynaptic boutons. We therefore compared the properties of optically evoked responses for stimulation over the postsynaptic cell and over axons $>200 \mu \mathrm{m}$ from the postsynaptic cell for the $\mathrm{PC} \rightarrow \mathrm{DCN}$ synapse and the $\mathrm{CA} 3 \rightarrow \mathrm{CA} 1$ synapse (Fig. $10 A, B)$. In both cases, AAV9 was used to express ChR2 and analysis was restricted to cells in which we recorded both over-axon and over-bouton stimulation.

At the $\mathrm{PC} \rightarrow$ DCN synapse, short-term plasticity was remarkably similar for over-bouton and over-axon stimulation with $2-100 \mathrm{~Hz}$ stimulus trains. There was no sign that over-bouton stimulation caused artificial synaptic depression (Fig. 10C,E). The performance of over-bouton stimulation was very different for the CA3 $\rightarrow$ CA1 synapse. Over-bouton stimulation at $10 \mathrm{~Hz}$ resulted in modest depression, whereas over-bouton stimulation at $50 \mathrm{~Hz}$ resulted in strong depression (Fig. 10D). A comparison of the frequency dependence of PSC10/PSC1 for electrical stimulation and optical stimulation over-axon and over-bouton revealed the largest differences between over-bouton and overaxon stimulation occurred at frequencies of $20 \mathrm{~Hz}$ and above (Fig. 10F). Although these findings illustrate the extent to which over-bouton stimulation can alter synaptic plasticity, such complications can be avoided simply by illuminating presynaptic fibers well away from the postsynaptic cell.

\section{Summary of light-evoked responses}

We compared the average normalized responses to the second and last stimulus of $50 \mathrm{~Hz}$ trains for electrically and optically evoked responses for each method of expressing ChR2 at all three synapses. The amplitude of the second response $\left(\mathrm{PSC}_{2} / \mathrm{PSC}_{1}\right)$ is often used to assesses whether a synapse is high $p$ (depresses) or low $p$ (facilitates), whereas the amplitude of the last response
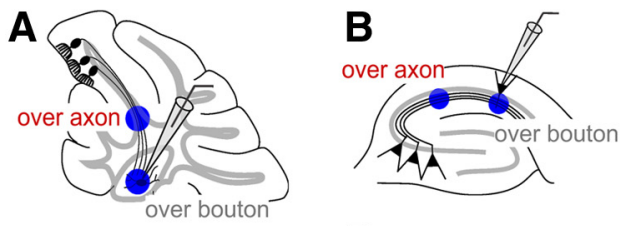

c

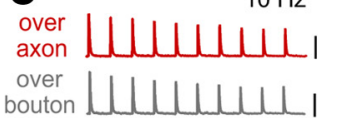

D

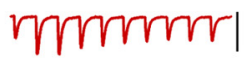
remprorr
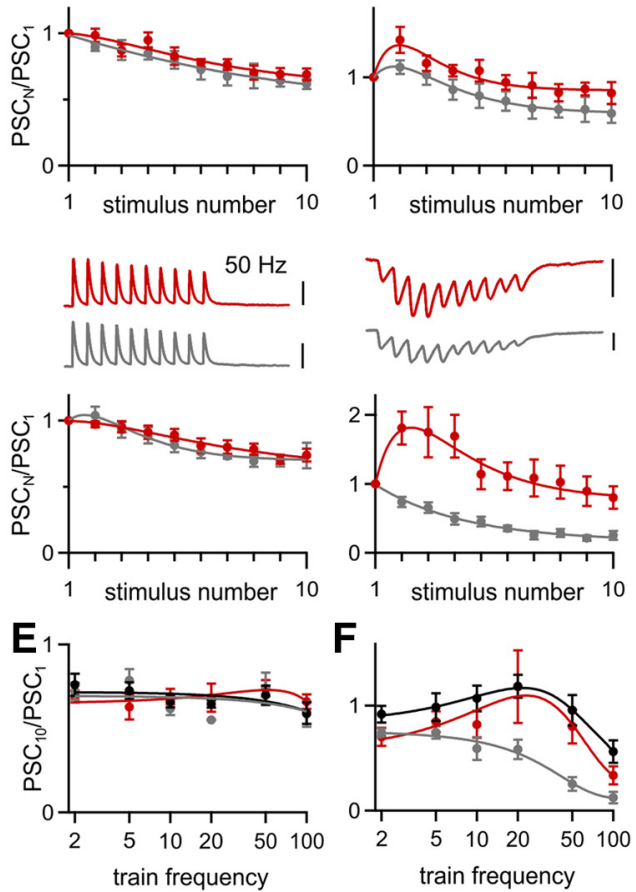

Figure 10. The performance of over-bouton stimulation is synapse dependent. ChR2 was expressed using AAV9-ChR2 and over-bouton and over-axon optical stimulation were compared for the $P C \rightarrow D C N(\boldsymbol{A})$ and the $C A 3 \rightarrow C A 1$ synapse $(\boldsymbol{B})$. C, D, Representative PSC s evoked by 10 and $50 \mathrm{~Hz}$ stimulation over-axon and over-bouton recorded from a single DCN $(C)$ or hippocampal CA1 (D) neuron and averaged normalized amplitudes for all cells in which responses to both stimuli were measured are shown for $\mathrm{PC} \rightarrow \mathrm{DCN}(\boldsymbol{B}, n=5)$ and for $\mathrm{CA} 3 \rightarrow$ CA1 synapses $(\boldsymbol{E}, n=6) . \boldsymbol{E}, \boldsymbol{F}$, Average normalized amplitude of the tenth PSC during stimulus trains of different frequencies, for electrical stimulation (black) and optical stimulation over-axon (red) and over-bouton (gray) for the $P C \rightarrow D C N(\boldsymbol{E})$ and $C A 3 \rightarrow$ CA1 synapse $(\boldsymbol{F})$. Scale bars: $\boldsymbol{C}$ $1000 \mathrm{pA} ; \boldsymbol{D}, 100 \mathrm{pA}$. Data are expressed as average \pm SEM.

$\left(\mathrm{PSC}_{10} / \mathrm{PSC}_{1}\right)$ provides a measure of the steady-state PSC. At the $\mathrm{PC} \rightarrow \mathrm{DCN}$ synapse, $\mathrm{PSC}_{2} / \mathrm{PSC}_{1}$ and $\mathrm{PSC}_{10} / \mathrm{PSC}_{1}$ did not differ significantly between electrically evoked PSCs and optically evoked PSCs for ChR2 expressed transgenically with AAV1 or with AAV9 (Fig. 11A). At the CA3 $\rightarrow$ CA1 synapse, we used eight different methods to express ChR2 in CA3 hippocampal pyramidal neurons (two transgenic, five viral, and one virally activated transgenic) with mixed effects on optically evoked synaptic plasticity (Fig. $11 B$ ). Purely transgenic approaches yielded optically evoked short-term plasticity similar to conventional electrical stimulation. In contrast, electrically and optically evoked synaptic plasticities were significantly different when ChR2 was expressed with AAV1, AAV5, and AAV8, but not with AAV9. At the grc $\rightarrow$ SC synapse, both AAV1 and AAV9 resulted in optically evoked responses that facilitated normally in response to the second stimulus, but depressed significantly in response to the last stimulus relative to electrical stimulation (Fig. 11C). However, the response to the last stimulus depressed significantly less with 
AAV9 than with AAV1. Unfortunately, our attempts to drive transgenic ChR2 expression at this synapse by crossing the $\alpha 6$-Cre and flox-hChR2 lines did not result in adequate expression levels, so it is unclear whether the deficits we observed in optically evoked synaptic plasticity resulted from problems with virally driven expression or from ChR2 stimulation itself.

\section{Method of ChR2 expression determines the reliability of synaptically driven circuit activity}

To date, ChR2 has been used sparingly to characterize synaptic physiology. More often, ChR2 is used to drive defined populations of neurons to study neural circuits (Gradinaru et al., 2009; Kravitz et al., 2010; Olsen et al., 2012). We investigated whether the synaptic depression we observed when ChR2 was expressed with AAV1 would impair the ability of optically activated synaptic inputs to drive postsynaptic activity at the $\mathrm{CA} 3 \rightarrow \mathrm{CA} 1$ synapse. We stimulated Shaffer collaterals either optically or electrically while recording from CA1 neurons in currentclamp conditions (Fig. 12). The electrical stimulus intensity and the size of the laser spot were adjusted to produce postsynaptic action potentials in response to $\sim 60 \%$ of single stimuli. For electrical stimulation with trains of 10 and $50 \mathrm{~Hz}$ in uninjected WT animals, each of the last nine stimuli usually evoked time-locked spikes. In contrast, optical stimulation in animals injected with AAV1-ChR2 evoked very little firing late in the train. However, optical stimulation in slices from Thy1-ChR2 animals evoked postsynaptic firing throughout the train, similar to electrical stimulation. The reliable postsynaptic firing produced by electrical stimulation and optical stimulation in Thy1-ChR2 animals is consistent with the observed facilitation of synaptic currents (Fig. 6), whereas the unreliable optical stimulation with AAV1-expressed ChR2 is consistent with the synaptic depression observed in these animals (Fig. 3). Therefore, the method of expressing ChR2 can strongly influence the manner in which optical stimulation drives neural circuit activity.

\section{Discussion}

We identified multiple difficulties in applying optogenetic approaches to studies of synaptic transmission, but found that, under the right experimental conditions, widely available ChR2 variants could be used to activate axons with physiologically relevant activity patterns and produce synaptic responses that were similar to electrically evoked responses. This was a surprise because previous studies have questioned whether ChR2 could be used to reliably activate axons at high frequencies. Instead, we found that deficits in optically evoked synaptic transmission could arise from either AAV expression vectors or stimulating over synaptic boutons. When ChR2 was expressed transgenically or using AAV9, optically and electrically evoked responses were similar.
A
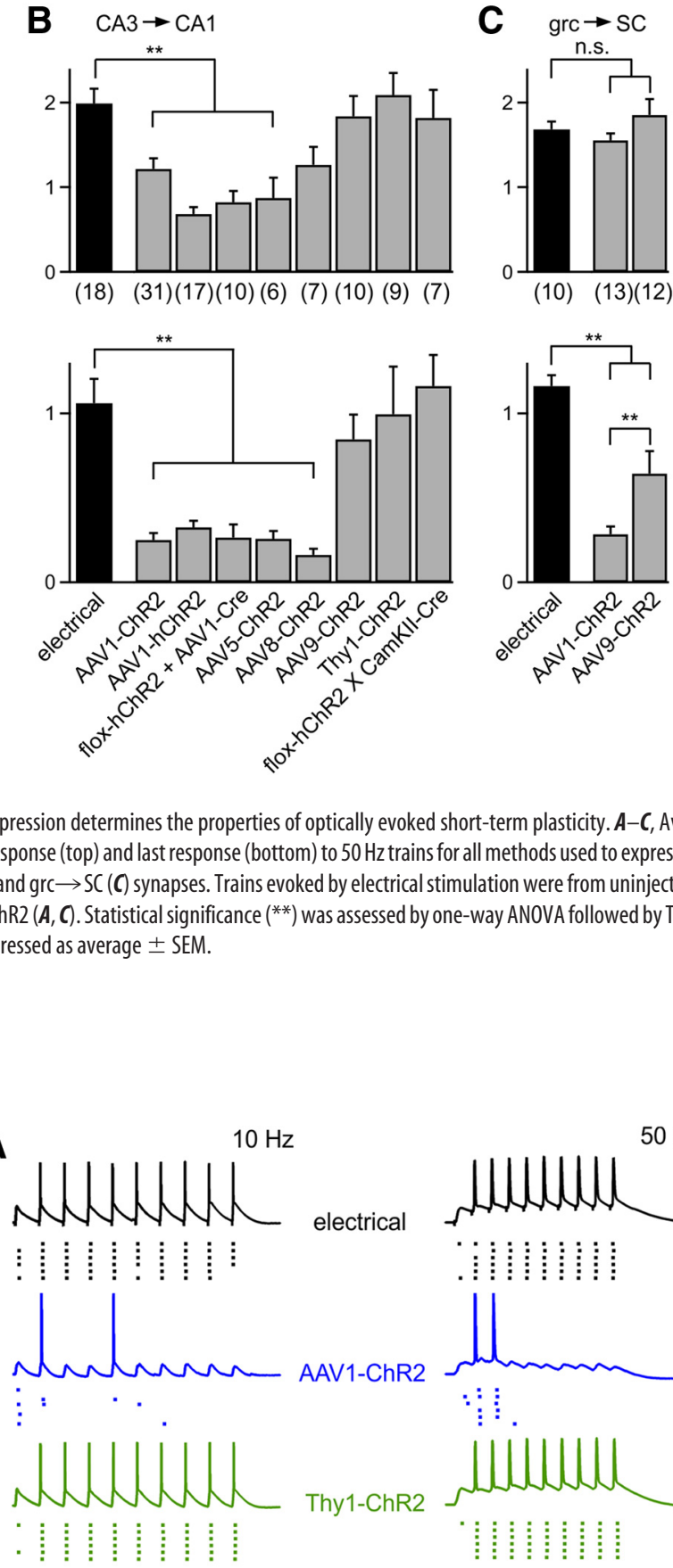

B

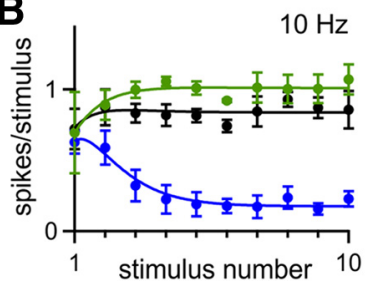

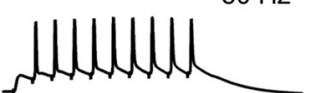

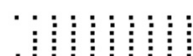
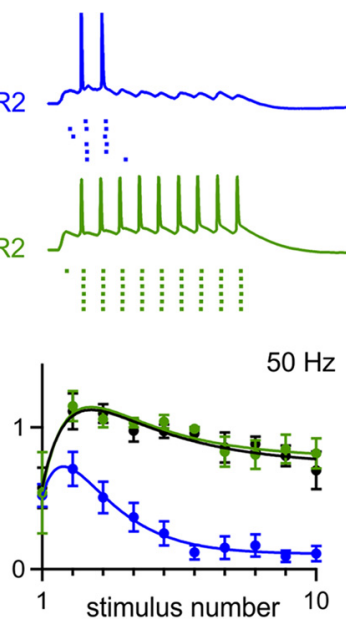

Figure 12. The method of ChR2 expression determines the reliability of synaptically driven circuit activity. $\boldsymbol{A}$, Current-clamp recordings from CA1 neurons. Action potentials were evoked by synaptic input from CA3 axons stimulated electrically (uninjected WT mice) and optically when ChR2 was expressed with AAV1-ChR2 or in Thy1-ChR2 mice. The stimulus intensity was adjusted to produce an action potential at the beginning of the train in $\sim 60 \%$ of trials. Spike raster plots below the current-clamp traces show firing during six trials. Examples are shown for 10 and $50 \mathrm{~Hz}$ stimulation. $\boldsymbol{B}$, Average number of spikes elicited by each stimulus in the train is shown for 10 and $50 \mathrm{~Hz}$ stimulation (electrical, $n=9$; AAV1-ChR2, $n=11$, Thy1-ChR2; $n=$ 10). Data are expressed as average \pm SEM. 


\section{Some AAV expression vectors can alter the properties of some synapses}

AAV serotypes influence synaptic responses in a highly synapsedependent manner. AAV1 led to artificial synaptic depression at the $\mathrm{CA} 3 \rightarrow \mathrm{CA} 1$ and grc $\rightarrow$ SC synapses, but not at the $\mathrm{PC} \rightarrow \mathrm{DCN}$ synapse. AAV5 and AAV8 also impaired synaptic transmission at the $\mathrm{CA} 3 \rightarrow \mathrm{CA} 1$ synapse, indicating that the problem was not specific to the AAV1 serotype. AAV9 mitigated the deleterious effects of viruses on short-term plasticity at CA3 $\rightarrow$ CA1 synapses, and to a certain extent at grc $\rightarrow$ SC synapses.

We tested several hypotheses to explain the observed deficits in optically evoked short-term plasticity when AAV1 was used to express ChR2. Initially, we assessed whether it was a result of the inherent inability of ChR2 to reliably stimulate axons, as had been previously proposed (Wang et al., 2007; Cruikshank et al., 2010; Cruikshank et al., 2012). The observation that axonal illumination reliably stimulated antidromic spikes in the soma of CA3 pyramidal cells indicated that this was not the case. Instead, AAV was implicated as the cause of impaired transmission because optically evoked synaptic plasticity was altered when AAV was used to either express ChR2 in WT animals or to express Cre in conditional ChR2 transgenic animals, whereas synaptic responses were normal in transgenic mice that expressed ChR2 without using AAV1. We also found that using AAV1 to produce strong and widespread expression of either Turbo RFP or ChR2 led to strong alterations in electrically evoked short-term plasticity, suggesting that some aspect of AAV1 transfection could alter the properties of short-term plasticity.

It is possible that some AAV serotypes induce reactive astrocytosis, which in turn alters synaptic strength (Ortinski et al., 2010). In the hippocampus, AAV5 induces reactive astrocytosis through an unknown mechanism, but AAV9 does not (AAV1 and AAV8 were not examined). Reactive astrocytosis reduced the magnitude of inhibition by downregulating the expression of glutamine synthetase, which in turn reduced the availability of GABA for synaptic release. This mechanism accounts for a reduction of inhibitory transmission, but cannot account for changes in the short-term synaptic plasticity of excitatory synapses. It is possible that reactive astrocytosis also affects the properties of short-term plasticity at excitatory synapses, but further experiments are needed to determine whether astrocytosis is the mechanism by which some AAV serotypes modify short-term plasticity at excitatory synapses. Regardless of the mechanism by which AAV1, AAV5, and AAV8 alter short-term plasticity, our findings suggest that these serotypes may not be suitable for many optogenetic applications and the use of AAV9 is preferable.

\section{Over-bouton stimulation}

For many applications, the easiest way to optically evoke large synaptic responses is to activate ChR2-labeled inputs with fullfield, over-bouton illumination. However, we found that illuminating directly over CA3 synaptic boutons led to artificial synaptic depression, whereas axonal stimulation at more distant sites produced more physiological synaptic responses. It is likely that the slow kinetics of ChR2 results in a prolonged depolarization of presynaptic boutons that affects endogenous voltage-gated channels and changes the probability of neurotransmitter release. Illuminating over axons at a distance from synapses provides the most reliable way of activating presynaptic inputs and axons can be stimulated with precise timing even at high frequencies.

In contrast, $\mathrm{PC} \rightarrow \mathrm{DCN}$ synaptic responses evoked by overbouton light stimulation were indistinguishable from those evoked electrically. This illustrates that problems associated with over-bouton stimulation are highly dependent on the synapse being studied. One potential explanation for the superior performance of over-bouton stimulation at $\mathrm{PC} \rightarrow \mathrm{DCN}$ synapses is that PCs are spontaneously active at high frequencies and express fast potassium channels at high density to rapidly repolarize action potentials. This may allow PC presynaptic boutons to overcome ChR2 conductances and rapidly repolarize after over-bouton stimulation.

\section{Widely available ChR2 variants allow synaptic activation at physiological frequencies}

Optogenetic techniques have proliferated rapidly across neuroscience in recent years, but ChR2 has not been fully exploited to investigate synaptic transmission. This may reflect a perception that ChR2 cannot reliably drive the physiological patterns of activity required for quantitative studies of synaptic short-term plasticity. Synaptic physiologists may have therefore approached the use of optogenetics cautiously. Efforts to characterize ChR2 and other microbial opsins have highlighted shortcomings such as inactivation and slow channel kinetics (Lin, 2011). To that end, great effort has gone into engineering ChR2 variants with greater light sensitivity, decreased desensitization and faster kinetics (Nagel et al., 2005; Lin et al., 2009; Gunaydin et al., 2010). Although improved ChR2 variants will doubtless be of great utility, we find that, with proper control of gene expression, ChR2 and hChR2 are already remarkable tools for the study of synapses.

\section{General strategy for using ChR2 to characterize synapses}

The possibility that over-bouton stimulation and the use of certain AAV serotypes can produce artificial synaptic depression must be taken into account for most but not all applications of ChR2. When determining basic synaptic properties, such as whether a synapse exists between two cell types or the identity of the neurotransmitter released, artificial synaptic depression is not an issue and transgenic animals or any of the AAV serotypes could be used. However, if the goals are to characterize whether synapses facilitate or depress, to determine responses to highfrequency stimulus trains, or to stimulate synapses in a realistic manner in vivo, then the means of expressing ChR2 and the manner of stimulation matter a great deal.

Our findings suggest that it is preferable to express ChR2 in the presynaptic cell of interest using transgenic animals either with an appropriate BAC transgenic line or by crossing Cre lines with flox-hChR2 mice, as we did for the CA3 $\rightarrow$ CA1 and $\mathrm{PC} \rightarrow \mathrm{DCN}$ synapses. Unfortunately, it may not always be possible to obtain an appropriate Cre line or to achieve sufficiently high levels of ChR2 expression, as was the case for grc $\rightarrow$ SC synapses.

If transgenic approaches are not an option, then AAV9 appears to be the preferable method for expressing ChR2. With this serotype, it was possible to obtain light-evoked responses that closely approximated electrically evoked responses at the $\mathrm{CA} 3 \rightarrow \mathrm{CA} 1$ and $\mathrm{PC} \rightarrow \mathrm{DCN}$ synapses. At the grc $\rightarrow$ SC synapse, the performance of AAV9 was superior to AAV1, although sustained optical stimulation still resulted in depression. This suggests that, unless electrical stimulation can be used to verify the properties of light-evoked responses, responses to sustained activation are difficult to interpret. Our findings at three synapses suggest that axonal stimulation of ChR2 expressed with AAV9 can at least be used to assess paired-pulse plasticity and estimate the release properties of a synapse.

In some cases, it is preferable to use over-bouton stimulation rather than axonal stimulation, which makes it easier to evoke 
synaptic responses. Over-bouton stimulation produced good responses at the $\mathrm{PC} \rightarrow \mathrm{DCN}$ synapse, but not at the CA3 $\rightarrow$ CA1 synapse. Therefore, a reasonable strategy to determine whether over-bouton stimulation can be used might be to compare responses evoked by over-bouton and over-axon stimulation. If there is good agreement in the short-term plasticity evoked by both methods of stimulation, then over-bouton stimulation can be used. However, if over-bouton stimulation produces artificial depression, then it should be avoided during synaptic characterization.

\section{References}

Aller MI, Jones A, Merlo D, Paterlini M, Meyer AH, Amtmann U, Brickley S, Jolin HE, McKenzie AN, Monyer H, Farrant M, Wisden W (2003) Cerebellar granule cell Cre recombinase expression. Genesis 36:97-103. CrossRef Medline

Arenkiel BR, Peca J, Davison IG, Feliciano C, Deisseroth K, Augustine GJ, Ehlers MD, Feng G (2007) In vivo light-induced activation of neural circuitry in transgenic mice expressing channelrhodopsin-2. Neuron 54: 205-218. CrossRef Medline

Boyden ES, Zhang F, Bamberg E, Nagel G, Deisseroth K (2005) Millisecondtimescale, genetically targeted optical control of neural activity. Nat Neurosci 8:1263-1268. CrossRef Medline

Creager R, Dunwiddie T, Lynch G (1980) Paired-pulse and frequency facilitation in the CA1 region of the in vitro rat hippocampus. J Physiol 299: 409-424. Medline

Cruikshank SJ, Urabe H, Nurmikko AV, Connors BW (2010) Pathway-specific feedforward circuits between thalamus and neocortex revealed by selective optical stimulation of axons. Neuron 65:230-245. CrossRef Medline

Cruikshank SJ, Ahmed OJ, Stevens TR, Patrick SL, Gonzalez AN, Elmaleh M, Connors BW (2012) Thalamic control of layer 1 circuits in prefrontal cortex. J Neurosci 32:17813-17823. CrossRef Medline

Ellender TJ, Huerta-Ocampo I, Deisseroth K, Capogna M, Bolam JP (2011) Differential modulation of excitatory and inhibitory striatal synaptic transmission by histamine. J Neurosci 31:15340-15351. CrossRef Medline

Fenno L, Yizhar O, Deisseroth K (2011) The development and application of optogenetics. Annu Rev Neurosci 34:389-412. CrossRef Medline

Gradinaru V, Mogri M, Thompson KR, Henderson JM, Deisseroth K (2009) Optical deconstruction of parkinsonian neural circuitry. Science 324: 354-359. CrossRef Medline

Gunaydin LA, Yizhar O, Berndt A, Sohal VS, Deisseroth K, Hegemann P (2010) Ultrafast optogenetic control. Nat Neurosci 13:387-392. CrossRef Medline

Harrison TC, Ayling OG, Murphy TH (2012) Distinct cortical circuit mechanisms for complex forelimb movement and motor map topography. Neuron 74:397-409. CrossRef Medline

Johansen JP, Hamanaka H, Monfils MH, Behnia R, Deisseroth K, Blair HT, LeDoux JE (2010) Optical activation of lateral amygdala pyramidal cells instructs associative fear learning. Proc Natl Acad Sci U S A 107:1269212697. CrossRef Medline

Kravitz AV, Freeze BS, Parker PR, Kay K, Thwin MT, Deisseroth K, Kreitzer AC (2010) Regulation of parkinsonian motor behaviours by optogenetic control of basal ganglia circuitry. Nature 466:622-626. CrossRef Medline

Ledri M, Nikitidou L, Erdelyi F, Szabo G, Kirik D, Deisseroth K, Kokaia M (2012) Altered profile of basket cell afferent synapses in hyper-excitable dentate gyrus revealed by optogenetic and two-pathway stimulations. Eur J Neurosci 36:1971-1983. CrossRef Medline

Lewis TL Jr, Mao T, Svoboda K, Arnold DB (2009) Myosin-dependent targeting of transmembrane proteins to neuronal dendrites. Nat Neurosci 12:568-576. CrossRef Medline

Lin JY (2011) A user's guide to channelrhodopsin variants: features, limitations and future developments. Exp Physiol 96:19-25. CrossRef Medline

Lin JY, Lin MZ, Steinbach P, Tsien RY (2009) Characterization of engineered channelrhodopsin variants with improved properties and kinetics. Biophys J 96:1803-1814. CrossRef Medline

Madisen L, Mao T, Koch H, Zhuo JM, Berenyi A, Fujisawa S, Hsu YW, Garcia AJ 3rd, Gu X, Zanella S, Kidney J, Gu H, Mao Y, Hooks BM, Boyden ES, Buzsáki G, Ramirez JM, Jones AR, Svoboda K, Han X, Turner EE, Zeng H (2012) A toolbox of Cre-dependent optogenetic transgenic mice for light-induced activation and silencing. Nat Neurosci 15:793-802. CrossRef Medline

Manabe T, Wyllie DJ, Perkel DJ, Nicoll RA (1993) Modulation of synaptic transmission and long-term potentiation: effects on paired pulse facilitation and EPSC variance in the CA1 region of the hippocampus. J Neurophysiol 70:1451-1459. Medline

Mathews PJ, Lee KH, Peng Z, Houser CR, Otis TS (2012) Effects of climbing fiber driven inhibition on purkinje neuron spiking. J Neurosci 32:17988 17997. CrossRef Medline

Nagel G, Brauner M, Liewald JF, Adeishvili N, Bamberg E, Gottschalk A (2005) Light activation of channelrhodopsin-2 in excitable cells of Caenorhabditis elegans triggers rapid behavioral responses. Curr Biol 15: 2279-2284. CrossRef Medline

Oertner TG, Sabatini BL, Nimchinsky EA, Svoboda K (2002) Facilitation at single synapses probed with optical quantal analysis. Nat Neurosci 5:657664. CrossRef Medline

Olsen SR, Bortone DS, Adesnik H, Scanziani M (2012) Gain control by layer six in cortical circuits of vision. Nature 483:47-52. CrossRef Medline

Ortinski PI, Dong J, Mungenast A, Yue C, Takano H, Watson DJ, Haydon PG, Coulter DA (2010) Selective induction of astrocytic gliosis generates deficits in neuronal inhibition. Nat Neurosci 13:584-591. CrossRef Medline

Palay SL, Chan-Palay V (1974) The cerebellar cortex: cytology and organization. New York: Springer.

Palkovits M, Magyar P, Szentágothai J (1971) Quantitative histological analysis of the cerebellar cortex in the cat. 3 . Structural organization of the molecular layer. Brain Res 34:1-18. CrossRef Medline

Person AL, Raman IM (2012) Purkinje neuron synchrony elicits time-locked spiking in the cerebellar nuclei. Nature 481:502-505. CrossRef Medline

Petreanu L, Huber D, Sobczyk A, Svoboda K (2007) Channelrhodopsin-2assisted circuit mapping of long-range callosal projections. Nat Neurosci 10:663-668. CrossRef Medline

Petreanu L, Mao T, Sternson SM, Svoboda K (2009) The subcellular organization of neocortical excitatory connections. Nature 457:1142-1145. CrossRef Medline

Piñol RA, Bateman R, Mendelowitz D (2012) Optogenetic approaches to characterize the long-range synaptic pathways from the hypothalamus to brain stem autonomic nuclei. J Neurosci Methods 210:238-246. CrossRef Medline

Royo NC, Vandenberghe LH, Ma JY, Hauspurg A, Yu L, Maronski M, Johnston J, Dichter MA, Wilson JM, Watson DJ (2008) Specific AAV serotypes stably transduce primary hippocampal and cortical cultures with high efficiency and low toxicity. Brain Res 1190:15-22. CrossRef Medline

Saunders A, Johnson CA, Sabatini BL (2012) Novel recombinant adenoassociated viruses for Cre activated and inactivated transgene expression in neurons. Front Neural Circuits 6:47. CrossRef Medline

Telgkamp P, Raman IM (2002) Depression of inhibitory synaptic transmission between Purkinje cells and neurons of the cerebellar nuclei. J Neurosci 22:8447-8457. Medline

Varga V, Losonczy A, Zemelman BV, Borhegyi Z, Nyiri G, Domonkos A, Hangya B, Holderith N, Magee JC, Freund TF (2009) Fast synaptic subcortical control of hippocampal circuits. Science 326:449-453. CrossRef Medline

Wang H, Peca J, Matsuzaki M, Matsuzaki K, Noguchi J, Qiu L, Wang D, Zhang F, Boyden E, Deisseroth K, Kasai H, Hall WC, Feng G, Augustine GJ (2007) High-speed mapping of synaptic connectivity using photostimulation in Channelrhodopsin-2 transgenic mice. Proc Natl Acad Sci U S A 104:8143-8148. CrossRef Medline

Wyatt KD, Tanapat P, Wang SS (2005) Speed limits in the cerebellum: constraints from myelinated and unmyelinated parallel fibers. Eur J Neurosci 21:2285-2290. CrossRef Medline

Xia Y, Driscoll JR, Wilbrecht L, Margolis EB, Fields HL, Hjelmstad GO (2011) Nucleus accumbens medium spiny neurons target nondopaminergic neurons in the ventral tegmental area. J Neurosci 31:78117816. CrossRef Medline

Xu B, Gottschalk W, Chow A, Wilson RI, Schnell E, Zang K, Wang D, Nicoll RA, Lu B, Reichardt LF (2000) The role of brain-derived neurotrophic factor receptors in the mature hippocampus: modulation of long-term potentiation through a presynaptic mechanism involving TrkB. J Neurosci 20:6888-6897. Medline

Zhang YP, Oertner TG (2007) Optical induction of synaptic plasticity using a light-sensitive channel. Nat Methods 4:139-141. CrossRef Medline

Zucker RS, Regehr WG (2002) Short-term synaptic plasticity. Annu Rev Physiol 64:355-405. CrossRef Medline 